\title{
Predicting Sense of Presence and Sense of Community in Immersive Online Learning Environments
}

\author{
Terry W. McClannon, Amy W. Cheney, Les L. Bolt, and Krista P. Terry \\ Appalachian State University
}

\begin{abstract}
This exploratory study is based on survey research conducted between 2010 and 2017, involving 1,053 graduate students using immersive online learning environments for their coursework. Investigators used course structural factors and student engagement factors to predict students' perceptions of community and presence in the online immersive space. Utilizing the Sense of Community II index (SCI-2) and the Community of Inquiry (CoI) survey median scores as cutoff scores for predicted outcomes, researchers demonstrated that purely online environments which encouraged student engagement in the online immersive space can enhance sense of presence and sense of community. In addition, students in graduate programs that used online immersive delivery methods longer developed a stronger sense of community. Both dependent measures proved to have stable subscale structures for this inquiry based on a confirmatory factor analysis.
\end{abstract}

Keywords: sense of community, sense of presence, community, presence, immersive learning environment, online learning, distance education

McClannon, T.W., Cheney, A.W., Bolt, L.L., \& Terry, K.P. Predicting sense of presence and sense of community in immersive online learning environments. Online Learning, 22(4), 141-159. doi:10.24059/olj.v22i4.1510

\section{Predicting Sense of Presence and Sense of Community in Immersive Online Learning Environments}

Almost two decades ago, the faculty members in the Instructional Technology program with a college of education at a large comprehensive university realized that something was missing from their online courses. Both faculty and students found that online courses conducted with their program lacked the interpersonal interactions, engagement, and collaborative environment necessary to facilitate the types of communities within courses that they desired. These faculty subscribed to the tenets of their college's social constructivist conceptual framework, but they noticed that despite their best efforts, many of these tenets were not being fully addressed in the online components of their courses; in particular, learning was not occurring through students' participation in a community of practice, nor was knowledge being socially constructed within such a community.

At that time, the university had adopted and was encouraging the use of a commonly used learning management system (LMS) to support the delivery of hybrid courses (i.e., those offering a combination of online and face-to-face learning), primarily as a supplement for students taking coursework at remote extension sites in rural areas of their state. While the faculty members using these tools believed that there was potential value in teaching and learning in an online environment, it was 
apparent to these educators that their students were not as engaged in the online component of the courses as they were when classes met face-to-face. Faculty found the online learning components to be passive, isolating, and utilitarian (albeit unintentionally) and lacking in opportunities for social connections to be made with other students or faculty. Students had little, if any, sense that others were present when logged into the LMS. There was no sense that others were online to help, collaborate, or interact. The only opportunities for students to feel part of a learning community were during the limited time spent in class, face-to-face with their peers and instructors, which was only available to students in hybrid cohorts. Fully online cohorts did not have the same opportunities for engagement and interaction. The online components provided by the LMS provided little to further the development of this community. Therefore, a new set of tools that afforded a new approach that better aligned with a social constructivist philosophy was needed.

Through extensive research and exploration, these faculty discovered an emerging technology that provided the type of online environment they desired: one that supported both scholarly research and social interactions between and among students and faculty. At that time immersive environments, specifically ActiveWorlds, was among the few alternatives to LMS platforms that could be modified to support online teaching and learning. This platform offered a persistent online immersive learning environment that provided multiple manifestations of presence (comprised of students, faculty, spaces, tools, curricular components, and artifacts) that closely aligned with the real world in which these students were accustomed to working. Faculty believed that this environment might have potential for creating an immersive online learning environment that was as engaging as the face-to-face classes they offered, if not more so. In fact, these faculty did notice that, over time, the interactions they had with their students, the interactions between students, and the students' interactions with the tools and resources in this new immersive environment began to resemble the learning communities of practice promoted by the aforementioned conceptual framework of their college.

Almost two decades later, the use of similar immersive online learning environments has expanded to multiple programs within the university and has become the online environment of choice for nearly two dozen faculty members. Over time, as immersive online platforms improved, the faculty explored the use of new environments to support their online courses. During the course of this study, there were two different platforms used to support immersive online learning at this institution. The faculty developed each of these customized platforms based on their curricular and pedagogical needs.

The initial online immersive environment used by faculty to support online learning was ActiveWorlds. ActiveWorlds was used as a client-based immersive environment that hosted a variety of landscapes, curricular resources, rooms and buildings to host class meetings, small group meetings, large forums, and opportunities for serendipitous interactions between faculty and students from each of the graduate programs utilizing the immersive space. The ActiveWorlds environment allowed faculty and students to customize an avatar with their preferred gender, race, hair color, and wardrobe from a limited pool of options. Users could move their customized avatars throughout the environment, which consisted of custom-built scenes and rooms developed by faculty and technical support staff. Faculty and staff engaged with each other by virtually walking through the immersive environment to meet other participants or by entering spaces designated for class meetings. Interactions in this environment were limited to a text chat feature that could be seen by everyone or used as a private chat. This environment had limited audio capabilities. Therefore, a third-party audio application was utilized for meetings that required audio, such as class meetings.

Given the limitations of ActiveWorlds at that time, the faculty chose to migrate to Teleplace, which later became OpenQwaq. This immersive environment possessed integrated features that greatly enhanced opportunities for interaction and collaboration within the environment. OpenQwaq provided features such as integrated audio, text chat, display panels for sharing Web pages, images and video, and 
the ability to open and collaboratively edit, in real time, documents, presentations, and images via the integrated Open Office suite. The environment also permitted faculty to establish sound regions, which isolated audio, throughout the immersive space. This allowed faculty and students to create small group meeting rooms within the environment, which closely replicated small group activities often found in traditional face-to-face classrooms. Figure 1 provides an illustration of the OpenQwaq environment and a few of its capabilities.

Bronack et al. (2008) describe the environment as a place where

students work and interact with others present in the world, often across the traditional boundaries of class, course, or program area. Students respond to feedback and advice offered by faculty and peers present in the environment when they are. Students are not limited only to their own course instructors, but instead are free to interact with and learn from instructors and peers from other courses and across multiple program areas. Students utilize tools and resources ever-present in the world in the context of authentic, hands-on activities, and projects. The multiple manifestations of presence enabled by this combination of content, context, and activity are the critical attributes for engagement among students in a social constructivist learning environment. Embedded within an immersive virtual world, they combine to create a new approach to teaching and learning that, in many ways, is significantly different from those on which educators traditionally rely and those which students typically expect. (p. 59)

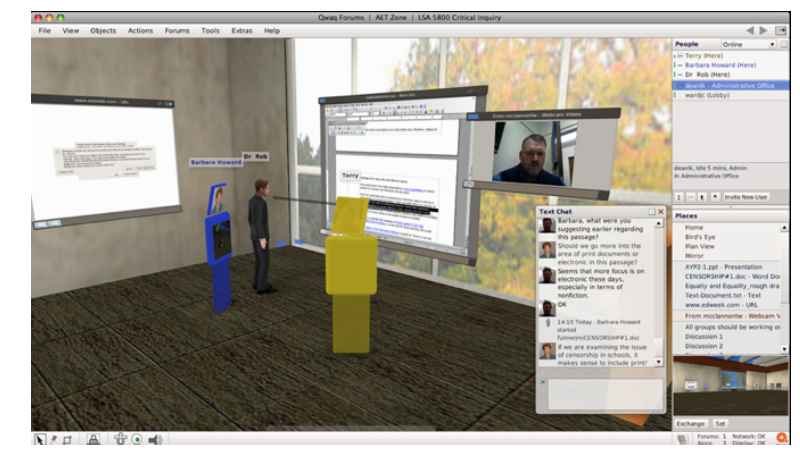

Figure 1. OpenQwaq immersive environment.

This environment permits students to truly immerse themselves in an online experience where they can engage, interact, collaborate, and partner with their instructors and classmates in meaningful ways that were not possible with an LMS platform. Faculty and students also found that they had a greater sense of presence and community while working in this online immersive environment.

During this last decade, the faculty have made many adaptations to the immersive environment and pedagogical approaches to improve on quality of the teaching and learning experiences offered. These faculty continue to explore opportunities to integrate new and innovative instructional models and practices utilizing these immersive platforms. However, the fundamental questions about the role of presence and the resulting formation of communities have remained and continue to guide the research done by these educators.

\section{Immersive Environments for Learning}

\section{Review of Related Literature}

A type of technology that consists of attributes and functions that can be leveraged to create the types of interactions that facilitate presence and community are immersive technologies. Although the 
concept of immersive technologies is one which defies easy definition, recent research into the field characterizes immersive technologies as being bound, or defined, by their ability create a perception of reality by surrounding users with authentic sensory experiences ("Immersion (virtual reality)," 2015). Dalgarno and Lee (2010) describe the concept of immersion as being one that relies upon the technical capabilities of a technology to render sensory stimuli. They additionally posit that the fidelity of the representation, along with the types of interactivity available within the environment, is what determines the degree of immersion.

Virtual worlds are one example of what have become more commonly known as immersive environments for learning. These types of technologies allow for users to be immersed, in some sensory way, in their experience. Gardner and Elliott (2014) cite the definition of immersive education tools, provided by the Immersive Education Initiative (http://immersiveeducation.org), as those giving participants a sense of "being there," which have capabilities that provide opportunities for connecting and communicating in ways comparable to traditional face-to-face environments.

These types of tools, including platforms such as virtual worlds, multiplayer games, augmented reality, and virtual reality, not only allow learners to experience a sense of being there, of presence, but allow for various types of interactions conducive to the formation of community. Within these types of platforms, users can construct and represent their own identities and interact with others in ways that emulate in-person interactions. These joint notions of presence, representation of self, and embodiment are keys in shaping user experience (Dickey, 2002).

With such affordances, virtual and immersive environments allow for types of interactions and a quality of interaction not available in more traditional Web-based learning systems:

The ability to sense the digital presence of others in environments such as virtual worlds, serious games, and simulations re-introduces the concept of social facilitation into our online endeavors in ways that we have relied upon in traditional spaces, but have been difficult or impossible to utilize in web-based ones. (Cheney \& Bronack, 2011, p. 80)

This type of immersion allows for a depth of interaction that goes beyond response to content being presented and enables faculty and students to interact in ways that traditional online learning systems simply did not allow. According to Dalgarno and Lee (2010), the sense of immersion leads to a sense of presence - the technical affordances of these environments lead to psychological experience. Therefore, the sense of being an embodied presence within an immersive experience can contribute to social interactions that help develop community and facilitate a high fidelity of experience and interaction. Given the importance of community in online teaching and learning, it is important to consider factors which enhance that sense of belonging. To do so was the purpose of this exploratory study.

\section{Formation of Online Communities}

Some researchers point to isolation and disconnectedness as primary causes of attrition in online courses (Angelino, Williams, \& Natvig, 2007; Kanuka \& Jugdev, 2006). As such, learners' sense of community is a common theme found in the literature related to online learning. These communities are referred to in the literature as "learning communities," "virtual communities," and "communities of practice," but all refer to the same general description of learner groups. Each refers to what Sadera, Robertson, Song, and Midon (2009) describe as "a group of participants in a distance-based environment with a shared purpose and the relationship among them including their sense of belonging, trust, and interaction" (p. 278). These online communities develop around a shared understanding and value of the immersive environment and exist as "real" communities in that they are simultaneously situated in the real world (Sanders \& Melton, 2010). 
Jonassen (1997) writes that learning technologies should be used to keep students active, constructive, collaborative, intentional, complex, contextual, conversational, and reflective. Wilson and Ryder (1996) add the term dynamic to this list, characterizing a technology-mediated learning community by the "distribution of control, commitment to generation and sharing of new knowledge, flexible and negotiated learning activities, autonomous community members, high levels of interaction, and shared goals and projects."

Scardamalia and Bereiter (1994) state that

schools need to be restructured as communities in which the construction of knowledge is supported as a collective goal, and the role of educational technology should be to replace classroom discourse patterns with those having more immediate and natural extensions to knowledge-building communities outside school walls. (p. 265)

The formation of such a community is an essential ingredient to the success of online learners. Wilson and Ryder (1996) point out that "learning cannot be separated from action" and that "community sharing [has] a consensual goal to support each other in learning." (p. 801) Learning is inextricably tied to the learners' participation in a community (Oliver \& Carr, 2009), and according to Perry and Edwards, the formation of an online learning community "serves as the foundation for a successful learning environment" (as cited in Scherer Bassani, 2011, p. 932).

\section{Communities of Inquiry}

Central to the idea of the creation of community is that the community's members be present with one another. The concepts of presence and co-presence are often found in discussion of pedagogy in virtual and immersive environments, though definitions of the terms vary. One useful definition of presence can be found in Rodgers and Raider-Roth (2006): "To be present is to come into relation, into connection, with students, their learning, subject matter and oneself' (p. 284).

This notion of presence as one of relationships and connections is of great importance in online learning experiences. In a 2005 study, students' perception of presence of other students and instructors in online classes significantly related to their positive attitudes about courses and levels of satisfaction with their own learning (Russo \& Benson, 2005).

Bronack et al. (2008), in their discussion of Presence Pedagogy (P2), note that manifestations of presence are the critical attributes for engagement among students in a social constructivist learning environment. In this pedagogical model designed to capitalize on the sense of presence in immersive environments, some similarities may be found to interactions in face-to-face environments; however, there are fundamental differences (Cheney et al., 2009, p. 91).

The Community of Inquiry $(\mathrm{CoI})$ theoretical framework is one that is frequently used as a basis for research on community and presence in online learning communities. It represents a process of creating a deep and meaningful learning experience through the development of three interdependent elements: social, cognitive, and teaching presence (Garrison, Anderson, \& Archer, 1999). The three elements of cognitive presence, social presence, and teaching presence all contain indicators, or characteristics, that better explicate the attributes of the presences, within each of the areas. Generally speaking, cognitive presence is the way in which learners construct meaning through discourse and reflection; social presence is the ability of participants to communicate and develop relationships within the community; and teaching presence is design and facilitation of social and cognitive processes.

The initial studies related to the CoI model aimed to use the CoI framework within text-based computer-mediated communication (CMC) settings in order to determine the effectiveness of such instructional settings. Since the initial application of the model to text-based CMC environments, the framework has been applied to a variety of online settings (Yang et al., 2016; Kovanović et al., 2017) 
and has included hybrid settings as well (Arbaugh, Bangert, \& Cleveland-Innes, 2010; Vaughan, 2010; Shea \& Bidjerano, 2010). Recent research has also involved the use of CoI to explore community in immersive environments (McKerlich \& Anderson, 2007; Burgess et al., 2010; McKerlich et al., 2011; Pellas, Peroutseas, \& Kanzanidis, 2013; Pellas \& Kanzanidis, 2014).

The three elements of the CoI framework, when present in an online environment for learning, allow for communication, collaboration, relationship building, and ultimately, the formation of learning communities. This type of collaborative learning involves learner sharing, learner interdependence, and active involvement of learners in activities (Yang, Wang, Shen, \& Han, 2007). It is not merely the interaction of those within in the community which leads to rich learning, but the ways in which meaningful activities and interactions are designed and encouraged:

Some have argued that in higher education, it is valuable and even necessary to create a community of inquiry where interaction and reflection are sustained; where ideas can be explored and critiqued; and where the process of critical inquiry can be scaffolded and modeled. Interaction in such an environment goes beyond social interaction and the simple exchange of information. A community of inquiry must include various combinations of interaction among content, teachers, and students. (Garrison \& Cleveland-Innes, 2005, p. 134)

\section{Sense of Community}

Research indicates that a desire to be a part of a wider social network is a basic human need and drive (Sayer, Beaven, Stringer, \& Hermena, 2013; Bastian \& Haslam, 2010). An individual's sense of community is associated with a range of positive outcomes, both in terms of physical and mental health. Further research indicates that there are four factors that contribute to an individual's sense of community: membership, influence, shared emotional connection, and reinforcement of need (McMillan \& Chavis, 1986). Sense of community has been found to be an important enabler for

offline community success. Increased participation and feelings of belonging can often be attributed to an individual's sense of community (Felton \& Shinn, 1992; Hunter \& Rigers, 1986). Sense of community has been linked to satisfaction with and commitment to a community (Burroughs \& Eby, 1998). McMillan and Chavis (1986) determined that a greater sense of community can enhance involvement and problem-focused coping behavior.

Sense of community in online communities can be very different than traditional face-to-face communities. Online communities may have limitations related to synchronousness, physical proximity, or spatial cohesiveness that are not issues in face-to-face interactions (Abfalter, Zaglia, \& Mueller, 2012). In addition, traditional social boundaries can become blurred through the use of anonymous screen names and/or avatars (Schroeder \& Axelsson, 2006).

Accurately measuring sense of community is a very difficult task given its complexity. However in 1986, the Sense of Community Index (SCI) scale was developed to measure for sense of community (Chavis, Hogge, McMillan, \& Wandersman, 1986). The SCI was based on theory that identifies four elements of a sense of community: membership, influence, meeting needs, and a shared emotional connection (McMillan \& Chavis, 1986). The SCI was developed to assess sense of community in traditional face-to-face environments and was not transferable to online or immersive environments. Chavis, Lee, and Acosta (2008) further refined the instrument with the development of the Sense of Community Index II (SCI-2). The newly developed scale demonstrated greater reliability of measures and proved to be more applicable to intercultural settings (Abfalter, Zaglia, \& Mueller, 2012). The SCI2 is based on the first SCI (Chavis, Hogge, McMillan, \& Wandersman, 1986). The SCI-2 was further tested and developed in a variety of communities and has investigated different age groups and diverse cultures. The SCI-2 consists of 24 closed-ended items and is measured using a Likert-type scale (not at all $=0$, somewhat $=1$, mostly $=2$, and completely $=3$; Chavis, Lee, \& Acosta, 2008). In the field of 
social sciences, SCI-2 is the measure most frequently used to measure sense of community ("Sense of Community Index (SCI) - Sense of Community," n.d.).

\section{Student Behavior and Course Structure Factors}

There is a lack of literature that focuses directly on the impacts of student effort and course structural factors on a sense of community and sense of presence in immersive settings. This is perhaps due to the rapidly evolving and complex nature of online learning and the tools available for use in the online space. There has, however, been research conducted on the nature of pedagogy and course structure and the effect on student participation and level of effort in online environments.

A 2005 case study examined whether online participation and patterns of participation were influenced by factors such as the technology and the interface used, content area experience, student roles, and information overload (Vonderwell \& Zachariah, 2005). In particular, the study was based on examining whether these pedagogical elements had an effect on participation and learning in online environments, particularly discussion boards. The researchers concluded that the pedagogical elements examined did have an effect and suggested that "there is a need to develop more pedagogically userfriendly online course interface and management systems" (p. 225). In addition, the authors concluded that "students need to be prepared for technology, learning management, pedagogical practice and the social roles required for online learning" (p. 225). The current study seeks to examine limited factors and their impact on social roles like community and presence.

Patron and Lopez (2011) reported a study on 212 students that examined how student effort and consistency of effort influenced student grades in an online course. Although the study failed to find a significant relationship between effort and grades, that study found that student consistency of effort in the online environment is a significant predictor of GPA. The authors suggested that amount of time online is less important than focused effort when online.

Cigdem and Ozturk (2016) investigated which factors predicted students' behavioral intention to engaged in online learning. They focused on student engagement in LMSs in a two-year postsecondary school in Turkey. Among their findings was that student satisfaction in online learning was influenced by students' perceived usefulness and perceived ease of use of the platform used. The three-step model used in the study led to the conclusion that "it is suggested that an increase in multimedia features and interactivity of the system could lead to higher perceived usefulness and ease of use" (p. 276). The conclusion is that all of these factors could lead to increases to student engagement in online systems.

These studies would seem to indicate that the interactive nature of online systems and the way in which they are employed within a course structure have an impact on students' perceptions about the course. Those perceptions about the concepts of community and presence are at the heart of the current study. While studies examining presence and community formation in immersive environments are becoming more prevalent, and new pedagogical models are now beginning to emerge, more research is necessary to understand the unique impact these environments have on students' sense of both community and presence.

\section{Purpose}

The purpose of this exploratory study was to examine available factors within the existing data set that may predict graduate students' development of a sense of presence (as measured by the CoI scale) and their development of a sense of collaborative community in an online immersive environment (as measured by the SCI-2 scale). Two questions were examined:

- What factors related to student engagement and/or course structure predict graduate learners' sense of community as measured by the SCI-2 scale scores? 
- What factors related to student engagement and/or course structure predict graduate learners' sense of presence as measured by the CoI scale scores?

\section{Respondents}

\section{Methods}

The respondents for this study included 1,053 unique graduate students enrolled in various graduate programs in a department within a college of education during the springs and summers of 2010 through 2017. The courses included courses at the master's, education specialist, and doctorate levels. An open call for responses was sent through course instructors to their students. Classes that included an immersive component and were either fully online or a hybrid of online and face-to-face meetings were included in the sample.

\section{Data Sources}

Presence and sense of community appear to be two distinct yet highly related concepts. Therefore, two different instruments were chosen to assess the development of community within the immersive learning environment: the SCI-2 and the CoI survey.

The SCI-2 is a 24-item Likert-type survey (with a scale of 1-4) that is used as a measure of sense of community and has been used as such in a variety of educational settings and a number of different cultures (Chavis, Lee, \& Acosta, 2008). The instrument includes subscales for reinforcement, membership, influence, and shared emotion. For this study, the overall alpha was .91, with subscale alphas ranging from .88 for membership to .92 for reinforcement.

The CoI instrument is a 34-item Likert-type survey (with a scale of 1-5) that assesses all three areas of teaching presence, cognitive presence, and social presence with a series of distinct item sets for each subscale. The instrument has been widely utilized and has been deemed a valid and reliable instrument for measuring the dimensions of the model within a variety of educational settings (Arbaugh et al., 2008; Swan et al., 2008). For this study, the overall alpha was .94, with alphas for the three subscales ranging from .95 to .97 .

The independent variables (i.e., predictors) available in this data set and selected for inclusion include Year of Survey (Group [ $n$ of at least 95 and less than 290, yearly]), type of cohort (Blended $[n=$ $378]$ or $100 \%$ Online $[n=675]$ ), Length of Time in Program (One year or less $(n=313)$, More than one year $[n=740])$, and amount of Time per Week spent in the online immersive environment (Less than 2 Hours $[n=387])$, or 2 Hours or More $[n=666])$.

\section{Confirmatory Factor Analysis of the Dependent Variable Instruments}

For the confirmatory factor analysis $(\mathrm{CFA} ; N=1,053)$ performed on the two dependent variables, the models were fit using lavaan version 0.5-23 (Rosseel, 2012) run in JASP version 0.9.01 (JASP Team, 2018). Maximum likelihood estimation (MLE) was used after indicators were checked for normality. JASP standardized the latent factors, allowing for free estimation of all factor loadings. The SCI-2 CFA is performed at the individual-item level of granularity, and the CoI CFA is performed at the questionset level.

The SCI-2 model fit was moderate and marginally acceptable, with a Tucker-Lewis Index (TLI) of .840 and root mean square error of approximation (RMSEA) of .108 with a $90 \%$ CI $(.104, .111)$. The full four-factor model fit the data significantly better than a baseline solution, $\chi^{2}(3)=2972.33, p<.001$. The indicators all showed significant positive factor loadings, with standardized coefficients ranging from .455 to .807 . There were also significant positive correlations among all four latent factors, indicating that participants that scored higher on one subscale were likely to score high on all of them. 
These results would seem to support the four-factor model of the SCI-2 at the individual-item level of granularity. (Chavis \& Pretty, 1999)

The CoI model fit was excellent, with a TLI of .968 and RMSEA of .093 with a 90\% CI (.083, .103). The full three-factor model fit the data significantly better than a baseline solution, $\chi^{2}(3)=280.87$, $p<.001)$. The indicators all showed significant positive factor loadings, with standardized coefficients ranging from .627 to .757 . There were also significant positive correlations among all three latent factors, indicating that participants that scored high in one area of presence also scored high on other presence subscales. These results provide support for the three-factor model at the question-set level of granularity (Arbaugh et al., 2008; Swan et al., 2008).

\section{Results}

In answering the research questions, all the predictor variables were categorical, and all except year of enrollment were collapsed to dichotomous variables based on an inspection of response frequencies to eliminate any blank cells. This process was also done for ease of analysis and to generate two-by-two contingency tables. The dependent variables (CoI and SCI-2) were converted to dichotomous variables. Normally continuous scale scores such as these would be analyzed in a way that takes advantage of the existing variance. There are a few rare instances when it is appropriate to take scale scores and convert them to categorical (normally dichotomous) variables (MacCallum, Zhang, Preacher, \& Rucker, 2002). One of those instances is when the scale score is extremely skewed toward one end of the scale. That is the case in this data set (Table 1). The maximum scale value for the SCI-2 is 4 and for the $\mathrm{CoI}$ is 5 . The median value was chosen as the cutoff point in converting the scale scores to dichotomous dependent outcomes to lessen the impact of outliers.

Table 1

Dependent Variable Descriptives

\begin{tabular}{lcc}
\hline & SCI-2 Overall & CoI Overall \\
\hline Valid & 973 & 904 \\
Missing & 81 & 150 \\
Mean & 2.729 & 4.204 \\
Median & 2.792 & 4.213 \\
Std. Deviation & 0.6553 & 0.6699 \\
\hline
\end{tabular}

A logistic regression analysis with a subsequent post hoc analysis on significant predictors using chi-square was completed for each research question. Logistic regression is appropriate for converted dichotomous dependent variables such as these since it does not require the same assumptions of normality and homogeneity of variance that most general linear model approaches require (Agresti, 2013). Logistic regression is also more useful for large sample sizes, as it uses maximum likelihood estimation (MLE) rather than ordinary least square (OLS) estimation. (McCullagh \& Nelder, 1989) The chi-square analysis is only being conducted to identify significant relationships; log odds ratios are not being used for effect size, as they are potentially inflated by large sample sizes (Pepe, Janes, Longton, Leisenring, \& Newcomb, 2003).

\section{What Factors Related to Student Engagement and/or Course Structure Predict Graduate Learners' Sense of Community as Measured by the SCI-2 Scale Scores?}

An overall SCI-2 scale score was significantly predicted by the amount of time per week that subjects spent in the online immersive environment and the type of cohort in which they were enrolled 
(Table 2). Subjects that spent more than two hours per week in the online immersive environment had higher overall scores than expected (Table 3). They were 1.85 times more likely to have scores in the group above the median than subjects who spent less time. Subjects in $100 \%$ online had higher overall scores than expected. They were 1.72 times more likely to have scores in the group above the median than subjects not in fully online experiences.

Table 2

SCI-2 Omnibus Tests of Model Coefficients

\begin{tabular}{lll|l|l}
\hline & & Chi-square & $d f$ & Sig. \\
\hline \multirow{3}{*}{ Step 1 } & Step & 51.66 & 4 & 0.00 \\
\cline { 2 - 5 } & Block & 51.66 & 4 & 0.00 \\
\cline { 2 - 5 } & Model & 51.66 & 4 & 0.00 \\
\hline
\end{tabular}

Table 3

SCI-2 Variables in the Equation

\begin{tabular}{|c|c|c|c|c|c|c|}
\hline & B & $S E$ & Wald & $d f$ & Sig. & $\operatorname{Exp}(B)$ \\
\hline $\begin{array}{l}\text { Length of Time } \\
\text { in Program }\end{array}$ & 0.17 & 0.14 & 1.45 & 1 & 0.23 & 1.18 \\
\hline Time per Week & 0.61 & 0.14 & 20.14 & 1 & 0 & 1.85 \\
\hline Cohort Type & 0.54 & 0.14 & 15.40 & 1 & 0 & 1.72 \\
\hline Group & 0.02 & 0.03 & 0.46 & 1 & 0.50 & 1.02 \\
\hline Constant & -2.09 & 0.41 & 26.29 & 1 & 0 & 0.12 \\
\hline
\end{tabular}

When examining the SCI-2 subscales (Table 4), Time per Week was a significant predictor of all subscore medians, including Reinforcement, Membership, Influence, and Shared Emotional. Subjects spending more than two hours per week scoring in the higher group on all subscale medians.

Cohort Type was also a significant predictor of all subscore medians, including Reinforcement, Membership, Influence, and Shared Emotional. Online cohort members scored in the higher group on all subscales' medians. 
Table 4

SCI-2 Subscales by Predictor

\begin{tabular}{ll|c|c|c}
\hline & $N$ & Chi-square & $d f$ & Sig \\
\hline $\begin{array}{l}\text { SCI-2 Reinforce Med * } \\
\text { Time Per Week }\end{array}$ & 1053 & 30.00 & 1 & 0.000 \\
\hline $\begin{array}{l}\text { SCI-2 Reinforce Med * } \\
\text { Cohort Type }\end{array}$ & 1,053 & 17.31 & 1 & 0.000 \\
\hline $\begin{array}{l}\text { SCI-2 Membership Med * } \\
\text { Time per Week }\end{array}$ & 1,053 & 21.46 & 1 & 0.000 \\
\hline $\begin{array}{l}\text { SCI-2 Membership Med * } \\
\text { Cohort Type }\end{array}$ & 1,053 & 17.29 & 1 & 0.000 \\
\hline $\begin{array}{l}\text { SCI-2 Influence Med * } \\
\text { Time per Week }\end{array}$ & 1,053 & 38.49 & 1 & 0.000 \\
\hline $\begin{array}{l}\text { SCI-2 Influence Med * } \\
\text { Cohort Type }\end{array}$ & 1,053 & 25.96 & 1 & 0.000 \\
\hline $\begin{array}{l}\text { SCI-2 Shared Emotional Med * } \\
\text { Time per Week }\end{array}$ & 1,053 & 21.17 & 1 & 0.000 \\
\hline $\begin{array}{l}\text { SCI-2 Shared Emotional Med * } \\
\text { Cohort Type }\end{array}$ & 1,053 & 8.48 & 1 & 0.004 \\
\hline
\end{tabular}

\section{What Factors Related to Student Engagement and/or Course Structure Predict Graduate Learners' Sense of Presence as Measured by the CoI Scale Scores?}

An overall CoI scale score was significantly predicted by the Length of Time in the Program and Type of Cohort in which subjects were enrolled (Table 5). Subjects enrolled more than one year in the program scored in the higher group on overall CoI median score (Table 6). They were 1.5 times more likely to have scores in the group above the median than newer students in the program. Subjects enrolled in online cohorts scored in the higher group on overall median CoI scores than predicted. They were 1.8 times more likely to have scores in the group above the median than subjects in less than fully online classes.

Table 5

CoI Omnibus Tests of Model Coefficients

\begin{tabular}{ll|c|c|c}
\hline & & Chi-square & $d f$ & Sig. \\
\hline \multirow{3}{*}{ Step 1 } & Step & 25.85 & 4 & 0 \\
\cline { 2 - 5 } & Block & 25.85 & 4 & 0 \\
\cline { 2 - 5 } & Model & 25.85 & 4 & 0 \\
\hline
\end{tabular}


Table 6

CoI Variables in the Equation

\begin{tabular}{lc|c|c|c|c|c}
\hline & $\mathrm{B}$ & $S E$ & Wald & $d f$ & Sig. & $\operatorname{Exp(B)}$ \\
\hline $\begin{array}{l}\text { Length of } \\
\begin{array}{l}\text { Time in } \\
\text { Program }\end{array}\end{array}$ & 0.378 & 0.138 & 7.45 & 1 & 0.006 & 1.46 \\
\hline $\begin{array}{l}\text { Time per } \\
\text { Week }\end{array}$ & 0.021 & 0.138 & 0.02 & 1 & 0.88 & 1.02 \\
\hline Cohort Type & 0.588 & 0.139 & 17.97 & 1 & 0 & 1.8 \\
\hline Group & 0.003 & 0.034 & 0.01 & 1 & 0.92 & 1.00 \\
\hline Constant & -1.35 & 0.4 & 11.40 & 1 & 0.001 & 0.26 \\
\hline
\end{tabular}

In examining the CoI subscales, Length of Time in the Program significantly predicted Teaching Presence (Table 7), Social Presence, and Cognitive Presence. In all three subscales, students with more than one year in the program are in the group having higher scores than the subscales medians.

Cohort Type significantly predicted Social Presence and Cognitive Presence. In both significant subscore predictions, subjects in online cohorts scored in the higher group on the subscale median scores.

Table 7

CoI Subscales by Predictors

\begin{tabular}{lc|c|c|c}
\hline & $N$ & Chi-square & $d f$ & Sig. \\
\hline $\begin{array}{l}\text { CoI Teaching } \\
\text { Pres Med * } \\
\text { Cohort Type }\end{array}$ & 1,053 & 2.22 & 1 & 0.14 \\
\hline $\begin{array}{l}\text { CoI Teaching } \\
\text { Pres Med * } \\
\text { Length of Time } \\
\text { in Program }\end{array}$ & 1,053 & 4.14 & 1 & 0.04 \\
\hline $\begin{array}{l}\text { CoI Social Pres } \\
\text { Med * Cohort } \\
\text { Type }\end{array}$ & 1,053 & 11.75 & 1 & 0.001 \\
\hline $\begin{array}{l}\text { CoI Social Pres } \\
\text { Med * Length of } \\
\text { Time in Program }\end{array}$ & 1,053 & 11.14 & 1 & 0.001 \\
\hline $\begin{array}{l}\text { CoI Cognitive } \\
\text { Pres Med * } \\
\text { Cohort Type }\end{array}$ & 1,053 & 9.27 & 1 & 0.002 \\
\hline $\begin{array}{l}\text { CoI Cognitive } \\
\text { Pres Med * } \\
\text { Length of Time } \\
\text { in Program }\end{array}$ & 1,053 & 5.32 & 1 & 0.02 \\
\hline
\end{tabular}




\section{Discussion}

In reviewing the outcomes of this study, the benefits of online immersive environments on students' sense of presence and sense of community are maximized by both the structure of the course in terms of cohort type (fully online or hybrid), students' time per week in immersive environment, and students' length of time in program in that environment. Students in courses that were conducted in the online immersive environment as opposed to those with more hybrid structures have a greater sense of community, and if students are required or encouraged to spend more time in the online immersive space, the sense of presence is enhanced. It would also appear that there are cumulative effects on sense of community based on a student's time within a program using online immersive methodology.

\section{Impact of Cohort Type on Sense of Community and Presence}

There are various levels and types of immersion related to teaching and learning online. The graduate programs involved in this study have two primary forms of formal meetings: hybrid (face-to-face classes and online meetings in an immersive environment) and online (fully online meetings in immersive environment). The type of class is determined by each program area based on student enrollments and pedagogical requirements.

The findings of this study indicate that students who are enrolled in fully online immersive programs have a greater sense of presence and community than their classmates enrolled in hybrid cohorts based on the CoI and SCI-2 scale results. According to the SCI-2 scale scores, students in 100\%-online immersive classes scored much higher than predicted and were 1.72 times more likely to have scores above the median than students not in fully online experiences. The CoI scale results indicated that subjects in fully online cohorts scored higher on overall median than predicted and were 1.8 times more likely to have scores above the median compared to less than fully online subjects. The subscales of Social Presence and Cognitive Presence were significantly predicted by cohort type.

These findings may seem counterintuitive for most. However, these findings were not that surprising to the researchers. The graduate program faculty involved in this study have invested a tremendous amount of time and energy in the development of this online immersive environment. They have been very intentional in their pedagogical approaches to ensure that students retain a sense of community and presence as part of their online coursework. One might think that hybrid courses would offer students more opportunities to build community; however, many program faculty have noted that there seems to be a propensity of faculty and students in hybrid courses to rely more heavily on the face-to-face meetings to engage with each other and depend less on the opportunities the online immersive environment offers. On the other hand, faculty who teach fully online cohorts are much more intentional in the ways that they engage students and create multiple opportunities for students to interact and collaborate with each other through small group work, reading groups, group projects, and more frequent online meetings, both formal and informal. The researchers also feel that students in these fully online programs are much more dependent upon each other for emotional and instructional support.

Although most faculty found that they are more accessible to their individual students in the fully online courses, many students are less prone to contact faculty directly for minor questions related to activities, assignments, or other concerns. However, they will contact classmates with whom they have developed relationships throughout their coursework to address those concerns. The faculty feel this is a major contributing factor to students' sense of community and presence in their fully online classes.

\section{Impact of Length of Time in Program on Sense of Community and Presence}

Researchers examined the overall CoI and SCI-2 scale results and found that the length of time that a student participated in a program that utilized an online immersive environment had a significant impact on their sense of presence and community. The CoI scale score specifically indicated that subjects enrolled more than one year in the program scored higher on the overall CoI media score and were 1.5 times more likely to have scored above the median than new students. Based on the length of time in the program, the 
subscales of Teaching Presence, Social Presence, and Cognitive Presence emerged as significant. The type of cohort was also a significant predictor of all subscore medians for the SCI-2 scale. Reinforcement, Membership, Influence, and Shared Emotional were significant predictors of sense of community. The fully online cohort members scored higher on all subscales.

The impact of length of time in a program and students' sense of community and presence was of interest to the researchers. Students' levels of immersion in LMS-type systems and immersive environments are often quite different from one another. Students' experiences in LMS environments tend to be focused more on the interaction and management of content of the course, whereas students in immersive environments tend to be much more interactive and collaborative with both content and the community of fellow students and faculty. With the immersive environments, the coursework and course interactions are interdependent and seamless. Therefore, students are part of a much more meaningful and engaging community of learners, whereby learning is supported through social and intellectual interactions.

These findings indicate the willingness of fully online groups to work together to accomplish mutually beneficial tasks and goals. The immersive environment provides students opportunities to interact with other members in much more intimate ways than traditional LMS asynchronous systems and even faceto-face environments. Interactions often take place in small groups that include text chats, audioconferencing, and videoconferencing, while collaboratively sharing resources within the immersive environment. Students utilize the variety of synchronous and asynchronous tools of the immersive environment that work best for their group dynamics. As a result of the high levels of close interactions, groups develop close personal and professional bonds that help to develop close communities of practice where individual and group needs are met.

\section{Impact of Time per Week on Sense of Community and Presence}

Through an analysis of collected data, researchers found that the amount of time spent in the immersive environment had a significant impact on the overall SCI-2 scores. Subjects that spent more than two hours per week in the online environment had overall higher scores than expected and were 1.85 times more likely to have scores above the median than subjects that spent less time. This finding should not be a revelation to anyone. In any environment, increased time spent in that environment will have an impact on one's sense of community and presence. Immersive learning environments should be no different. Therefore, subjects spending more than two hours in the online immersive environment had a greater sense of community than those who spent less.

The findings of this study are counter to what many think about online teaching and learning today. Online courses are often considered to be inferior or of lesser quality than traditional face-to-face courses. There is an unwritten expectation that students in online courses will work in isolation and have very few opportunities to engage with their instruction, much less with classmates. This study illustrates that there are meaningful ways in which faculty can engage students in online environments. Online immersive environments have great potential create instructional opportunities that can foster students' sense of community and co-presence in ways that are instructionally beneficial. If these platforms are utilized appropriately, we feel that fully online programs will develop a greater sense of community and presence that will lead to improve student outcomes. Lock (2002) identifies the four cornerstones of a learning community as collaboration, communication, interaction, and participation. The findings of this study suggest that the way in which courses with immersive activity are constructed can impact sense of presence and that programs that engage students in immersive activity from the beginning of the program and then throughout can enhance the sense of community.

\section{Limitations}

We acknowledge that the study of community and presence within the online immersive environment is in its infancy and still very much evolving. Inquiry in this area may be limited by the lack of sufficient instrumentation and the lack of a clear understanding of the confounding factors, such as differences in pedagogy. 
Particularly limiting to this study is the transition from one online immersive platform to another, which may have impacted students' perceptions of community and presence. How that might have impacted results is unknown. Even though the year in which the student took the survey was a reasonable proxy for different online immersive platforms, it was not significantly predictive of any SCI-2 or CoI subscales. The addition of new collaborative tools in different platforms could have led to new pedagogical practices that may have had a confounding impact on students' sense of community and presence.

Lastly, the researchers did not attempt to assess the individual pedagogical approaches used by faculty from the various programs. Differences in pedagogy and teaching quality unrelated to the online immersive platforms may have had additional confounding effects. Variations in styles, difficulty of content, quality of instruction practices, interactions, and resources could potentially impact student perceptions.

\section{Implications for Future Research}

To increase the participant pool for this research, we plan to continue our research within the online immersive learning environment. Data collection will continue at periodic times throughout the academic year to accurately assess student perceptions of community and presence. As the data set grows, we will be able to provide a more powerful analysis of community and presence within the online immersive environment.

New instrumentation needs to be explored. Although the SCI-2 and the CoI are established instruments with acceptable to excellent model fit for this data set, that does not mean they are measuring valid concepts for this learning environment. Perhaps an instrument or instruments with greater validity to purely online immersive environments need to be identified or developed if the research is to go more deeply into the pedagogical and programmatic impacts of the online immersive environments.

Continued research is needed to ensure that the study results are consistent within different platforms. Given that some students received instruction and interacted with peers and faculty perhaps in more than one online immersive learning environment, it is imperative that researchers compare activities that were perceived to produce students' sense of community and presence in a setting where the tools and interactions are consistent. It is likely that new platforms will continue to be explored and used, so all future student responses to surveys will need to be responsive to different approaches.

\section{Conclusion}

As online learning becomes more ubiquitous, it is vital for researchers to understand factors which lead to student success in these environments. Traditional systems which reinforce teacher-driven, content delivery methods can lead to frustration and even attrition on the part of many students.

Previous research has indicated that community is fundamental to learning (Oliver \& Carr, 2009). Models such as CoI and SCI-2 can help researchers begin to understand those factors which lead students to feel present, connected, and part of a meaningful community-and to experience success. Immersive environments are uniquely positioned as tools to help instructors achieve these goals.

Proponents of the use of immersive environments in education have often espoused the notion that important concepts, such as community and presence, can be replicated, if not improved, in these settings. The findings of this study support the belief that well-constructed and concentrated online environments which foster student immersion may actually enhance students' sense of presence and community. 


\section{References}

Abfalter, D., Zaglia, M. E., \& Mueller, J. (2012). Sense of virtual community: A follow up on its measurement. Computers in Human Behavior, 28, 400-404.

Agresti, A. (2013). Categorical data analysis (3rd ed.). Somerset, NJ: Wiley.

Angelino, L. M., Williams, F. K., \& Natvig, D. (2007). Strategies to engage online students and reduce attrition rates. Journal of Educators Online, 4(2), 1-4. Retrieved from https://files.eric.ed.gov/fulltext/EJ907749.pdf

Arbaugh, J. B., Bangert, A., \& Cleveland-Innes, M. (2010). Subject matter effects and the Community of Inquiry (CoI) framework: An exploratory study. The Internet and Higher Education, 13(12), 37-44. Elsevier Inc. doi:10.1016/j.iheduc.2009.10.006

Arbaugh, J., Cleveland-Innes, M., Diaz, S., Garrison, D., Ice, P., Richardson, J., \& Swan, K. (2008). Developing a Community of Inquiry instrument: Testing a measure of the Community of Inquiry framework using a multi-institutional sample. The Internet and Higher Education, 11(3-4), 133-136. Elsevier Inc. doi:10.1016/j.iheduc.2008.06.003

Bastian, B., \& Haslam, N. (2010). Excluded from humanity: The dehumanising effects of social ostracism. Journal of Experimental Social Psychology, 46, 107-113.

Bronack, S., Sanders, R., Cheney, A., Riedl, R., Tashner, J., \& Matzen, N. (2008). Presence pedagogy: Teaching and learning in a 3D immersive world. International Journal of Teaching and Learning in Higher Education, 20(1), 59-69. Retrieved from http://www.isetl.org/ijtlhe/pdf/IJTLHE453.pdf

Burgess, M. L., Slate, J. R., Rojas-LeBouef, A., \& LaPrairie, K. (2010). Teaching and learning in Second Life: Using the Community of Inquiry (CoI) model to support online instruction with graduate students in instructional technology. The Internet and Higher Education, 13(1-2), 8488. Elsevier B.V. doi:10.1016/j.iheduc.2009.12.003

Burroughs, S. M., \& Eby, L. T. (1998). Psychological sense of community at work: A measurement system and explanatory framework. Journal of Community Psychology, 26(6), 509-532.

Chavis, D. M., Hogge, J. H., McMillan, D. W., \& Wandersman, A. (1986). Sense of community through Brunswik's lens: A first look. Journal of Community Psychology, 14(1), 24-40.

Chavis, D. M., Lee, K. S., \& Acosta, J. D. (2008). The Sense of Community (SCI) revised: The reliability and validity of the SCI-2. Paper presented at the 2 nd International Community Psychology Conference, Lisboa, Portugal.

Chavis, D. M., \& Pretty, G. M. H. (1999). Sense of community: Advances in measurement and application. Journal of Community Psychology, 27(6), 635-642. http://dx.doi.org/10.1002/(SICI)1520-6629(199911)27:6<635::AID-JCOP1>3.0.CO;2-F

Cheney, A. W., \& Bronack, S. C. (2011). Presence pedagogy as framework for research in virtual environments. International Journal of Gaming and Computer-Mediated Simulations, 3(1), 7985. doi:10.4018/jgcms.2011010106

Cheney, A., Sanders, R., Matzen, N., \& Tashner, J. (2009). Instructional design and pedagogical issues with Web 2.0 tools. In T. Kidd \& I. Chen (Eds.) Wired for learning: An educator's guide to Web 2.0. Charlotte, NC: Information Age Publishing. 
Cigdem, H., \& Ozturk, M. (2016). Factors affecting students' behavioral intention to use LMS at a Turkish post-secondary vocational school. International Review of Research in Open and Distributed Learning, 17(3), 277-295.

Dalgarno, B., \& Lee, M. J. W. (2010). What are the learning affordances of 3-D virtual environments? British Journal of Educational Technology, 41(1), 10-32 doi:10.1111/j.14678535.2009.01038.x

Dickey, M. D. (2002). Constructing learners in 3D: An investigation of design affordances and constraints of active worlds educational universe. Presented at the National Convention of the Association for Educational Communications and Technology, Dallas, TX.

Felton, B. J., \& Shinn, M. (1992). Social integration and social support: Moving 'social support' beyond the individual level. Journal of Community Psychology, 20(1), 103-115.

Gardner, M. R., \& Elliott, J. B. (2014). The Immersive Education Laboratory: Understanding affordances, structuring experiences, and creating constructivist, collaborative processes, in mixed-reality smart environments. EAI Endorsed Transactions on Future Intelligent Educational Environments, 1(1), e6. http://doi.org/10.4108/fiee.1.1.e6

Garrison, D., Anderson, T., \& Archer, W. (1999). Critical inquiry in a text-based environment: Computer conferencing in higher education. The Internet and Higher Education, 2(2-3), 87105. doi:10.1016/S1096-7516(00)00016-6

Garrison, D. R., \& Cleveland-Innes, M. (2005). Facilitating cognitive presence in online learning: Interaction is not enough. American Journal of Distance Education, 19(3), 133-148. http://doi.org/10.1207/s15389286ajde1903_2

Hunter, A., \& Rigers, S. (1986). The meaning of community in community mental health. Journal of Community Psychology, 14(1), 55-71.

Immersion (virtual reality). (2018, May 22). In Wikipedia, the free encyclopedia. Retrieved from http://en.wikipedia.org/w/index.php?title=Immersion_(virtual_reality)\&oldid=642731454

Jonassen, D. H. (1997). INSYS 527: Designing constructivist learning environments. Retrieved July 20, 2011, from http://www.coe.missouri.edu/ jonassen/INSYS527.html

Kanuka, H., \& Jugdev, K. (2006). Distance education MBA students: An investigation into the use of an orientation course to address academic and social integration issues. Open Learning, 21(2), 153-166. doi:10.1080/02680510600715578

Kovanović, V., Joksimović, S., Poquet, O., Hennis, T., Čukić, I., de Vries, P., ... Gašević, D. (2017). Exploring communities of inquiry in massive open online courses. Computers \& Education, 119, 44-58. https://doi.org/10.1016/j.compedu.2017.11.010

MacCallum, C., Zhang, S., Preacher, K., \& Rucker, D. (2002). On the practice of dichotomization of quantitative variables. Psychological Methods, 7(1), 19-40.

McCullagh, P., \& Nelder, J. A. (1989). Generalized linear models (2nd ed.). London: Chapman and Hall.

McKerlich, R., \& Anderson, T. (2007). Community of inquiry and learning in immersive environments. Journal of Asynchronous Learning Networks, 11(4), 35-53. Retrieved from https://pdfs.semanticscholar.org/bd3b/2e2100a1369baf1e7dbafdeb1f8af4816e94.pdf 
McKerlich, R., Riis, M., Anderson, T., \& Eastman, B. (2011). Student perceptions of teaching presence, social presence, and cognitive presence in a virtual world. MERLOT Journal of Online Teaching and Learning, 7(3). Retrieved from http://jolt.merlot.org/vol7no3/mckerlich_0911.htm

McMillan, D., \& Chavis, D. (1986). Sense of community: A definition and theory. Journal of Community Psychology, 14, 6-23.

Oliver, M., \& Carr, D. (2009). Learning in virtual worlds: Using communities of practice to explain how people learn from play. British Journal of Educational Technology, 40(3), 414-426. https://doi.org/10.1111/j.1467-8535.2009.00948.x

Patron, H., \& Lopez, S. (2011). Student effort, consistency, and online performance. The Journal of Educators Online, 8(2), 1-11.

Pellas, N., \& Kazanidis, I. (2014). The impact of computer self-efficacy, situational interest and academic self-concept in virtual communities of inquiry during the distance learning procedures through Second Life. World Wide Web, 17(4), 695-722. https://doiorg.proxy006.nclive.org/10.1007/s11280-013-0266-9

Pellas, N., Peroutseas, E., \& Kazanidis, I. (2013). Virtual communities of inquiry (VCOI) for learning basic algorithmic structures with open simulator and Scratch4OS: A case study from the secondary education in Greece. In Proceedings of the 6th Balkan Conference in Informatics (pp. 187-194). doi:10.1145/2490257.2490278.

Pepe, M., Janes, H., Longton, G., Leisenring, W., \& Newcomb, P. (2004). Limitations of the odds ratio in gauging the performance of a diagnostic, prognostic, or screening marker. American Journal of Epidemiology, 159(9), 882-890.

Rodgers, C. R., \& Raider-Roth, M. B. (2006). Presence in teaching. Teachers \& Teaching, 12(3), 265287. doi:10.1080/13450600500467548

Rosseel, Y. (2012). lavaan: An R package for structural equation modeling. Journal of Statistical Software, 48(2), 1-36. Retrieved from https://www.jstatsoft.org/article/view/v048i02

Russo, T., \& Benson, S. (2005). Learning with invisible others: Perceptions of online presence and their relationship to cognitive and affective learning. Educational Technology and Society, 8(1), 54-62. Retrieved from http://www.jstor.org/stable/jeductechsoci.8.1.54

Sadera, W. A., Robertson, J., Song, L., \& Midon, M. N. (2009). The role of community in online learning success. MERLOT Journal of Online Teaching and Learning, 5(2), 277-284.

Retrieved from http://jolt.merlot.org/vol5no2/sadera_0609.pdf

Sanders, R. L., \& Melton, S. (2010). The AETZone experience: A qualitative analysis of the use of presence pedagogy in a 3D immersive learning environment. MERLOT Journal of Online Learning and Teaching, 6(1). Retrieved from http://jolt.merlot.org/vol6no1/sanders_0310.pdf

Sayer, E., Beaven, A., Stringer, P., \& Hermena, E. (2013). Investigating sense of community in primary schools. Educational \& Child Psychology, 30(1), 9-25.

Scardamalia, M., \& Bereiter, C. (1994). The systemic vision of the educational learning. The Journal of the Learning Sciences, 3(3), 265-283.

Scherer Bassani, P. B. (2011). Interpersonal exchanges in discussion forums: A study of learning communities in distance learning settings. Computers \& Education, 56(4), 931-938. Retrieved from https://www.learntechlib.org/p/50822/ 
Schroeder, R., \& Axelsson, A. S. (2006). Avatars at work and play: Collaboration and interaction in shared virtual environments. Dodrecht, The Netherlands: Springer.

Sense of Community Index (SCI) - Sense of Community. (n.d.). Retrieved from https://www.senseofcommunity.com/soc-index/

Shea, P., \& Bidjerano, T. (2010). Learning presence: Towards a theory of self-efficacy, self-regulation, and the development of a communities of inquiry in online and hybrid learning environments. Computers \& Education, 55(4), 1721-1731. Elsevier Ltd. doi:10.1016/j.compedu.2010.07.017

Swan, K. P., Richardson, J. C., Ice, P., Garrison, R., Cleveland-Innes, M., \& Arbaugh, B. (2008). Validating a measurement tool of presence in online communities of inquiry. E-mentor, 2(24), 1-12. Retrieved from www.e-mentor.edu.pl/eng

Vaughan, N. D. (2010). A hybrid community of inquiry approach: Linking student engagement and course redesign. The Internet and Higher Education, 13(1-2), 60-65. Elsevier Inc. doi:10.1016/j.iheduc.2009.10.007.

Vonderwell, S., \& Zachariah, S. (2005). Factors that influence participation in online learning. Journal of Research on Technology in Education, 38(2), 213-230

Wilson, B., \& Ryder, M. (1996). Dynamic learning communities: An alternative to designed instructional systems. Proceedings of Selected Research and Development Presentations at the 1996 National Convention of the Association for Educational Communications and Technology. Indianapolis, IN. Retrieved from https://files.eric.ed.gov/fulltext/ED397847.pdf

Yang, J. C., Quadir, B., Chen, N-S., \& Miao, Q. (2016). Effects of online presence on learning performance in a blog-based online course. Internet and Higher Education, 30, 11-20. https://doi.org/10.1016/j.iheduc.2016.04.002

Yang, F., Wang, M., Shen, R., \& Han, P. (2007). Community-organizing agent: An artificial intelligent system for building learning communities among large numbers of learners. Computers and Education, 49(2), 131-147. doi:10.1016/j.compedu.2005.04.019 